\title{
ASSISTÊNCIA SOCIAL ESPÍRITA E CULTURA DA FILANTROPIA: APROXIMAÇÕES E DISTINÇÕES ENTRE CARIDADE E AÇÃO CIDADÃ ${ }^{1}$
}

\author{
Norberto Decker ${ }^{2}$
}

Resumo: Por meio de trabalho de campo em duas instituições espíritas de Curitiba, Brasil, que desenvolvem atividades de assistência social, identifico os modos de agir, de pensar e de crer das instituições espíritas vinculadas à área de ação social com o objetivo de apreender a perspectiva dos diferentes agentes sociais envolvidos em atividades definidas como prática da caridade e da assistência social. Aponta a etnografia para um rumo que a ação social espírita vem tomando nas últimas duas décadas ao se apropriar do conceito de cidadania e relacioná-lo ao de caridade, na busca de se produzir novas formas de atuação social do Espiritismo, tais como a inserção deste em fóruns organizados pela sociedade civil e em conselhos do Estado. Atesta-se, assim, a ocorrência de uma reavaliação das funções sociais da religião junto ao Estado na área das políticas sociais de combate à pobreza, indicando valores religiosos como uma das motivações de participação cidadã.

Palavras-chave: Caridade; Espiritismo; Assistência social; Cidadania.

Abstract: Through fieldwork in two spiritualists institutions of Curitiba, Brazil, that develop social welfare activities, we sought to identify the ways of acting, thinking and believing of the spiritualists institutions linked to the area of social action, aimed to grasp the perspective of different actors involved in activities defined as the practice of charity and social welfare. Ethnography points to a course that spiritism social action has been taking over the past two decades by appropriating

1 Este artigo decorre de minha monografia de conclusão de curso Caridade e Assistência Social Espírita: imbricaçôes do auxílio e da ação cidadã, defendida em julho de 2010 no Departamento de Antropologia da Universidade Federal do Paraná. Agradeço a Sandra Jacqueline Stoll (orientadora do trabalho) e a Maria Inês Smiljanic por suas apreciações e sugestôes. $\mathrm{O}$ artigo presta homenagem à Rosângela Digiovanni (in memoriam).

2 Mestre e doutorando em Antropologia Social (PPGAS/UFRGS).

Contato: decker.norberto@gmail.com.

Debates do NER, Porto Alegre, ano I6, N. 27, P. 385-405, JAn./Jun. 2015 
the concept of citizenship and relate it to charity, seeking to produce new forms of social action of Spiritualism, such as the insertion of this in forums organized by civil society and in the state councils. Thus, it testifies to the occurrence of a reassessment of the social functions of religion by the state in the area of social policies to combat poverty, indicating religious values as one of the motivations of citizen participation.

Keywords: Charity; Spiritualism; Social care; Citizenship.

\section{INTRODUÇÃO}

Em meados do século XIX, alguns jornais já informavam a existência de "reuniōes espiritualistas", principalmente em casas de pessoas de classe média, nas quais alguns fenômenos ("mesas girantes", batidas e ruídos) eram praticados, sobretudo como forma de entretenimento. Eduardo Arraia (1996) relata que, por volta de 1853, um grupo de pessoas reunia-se sistematicamente na cidade do Rio de Janeiro a fim de estudar os "assuntos espiritualistas", grupo que contava com algumas pessoas bastante influentes da época, como o historiador e homeopata Melo Morais, o Visconde de Uberaba, o Marquês de Olinda, dentre outros.

No entanto, considera-se que a doutrina de Allan Kardec chegou ao Brasil em torno de 1860, tendo como primeiros adeptos um pequeno grupo de imigrantes franceses, no qual um dos destaques era Casimir Lieutaud, na época, diretor do Colégio Francês do Rio de Janeiro e responsável pela publicação do primeiro livro de temática espírita (Les temps sont arrivés, impresso na língua francesa, em 1860). Mas foi na Bahia que o espiritismo mais firmemente se organizou; em 1865, foi formado o primeiro centro espírita, o Grupo Familiar do Espiritismo, cuja direção ficou por conta do Dr. Luís Olímpio Teles de Menezes. Enquanto a doutrina restringia-se aos imigrantes e pequenos grupos elitizados, ela não causou incômodo, mas as coisas começaram a mudar quando passou a ter maior adesão entre as classes populares.

Debates do NER, Porto Alegre, Ano i6, N. 27, P. 385-405, JAN./Jun. 2015 
Damazio (1994) afirma que a expansão do espiritismo no Brasil entre as classes populares teve como característica fundamental a prática da caridade, centrada no atendimento médico (receitismo homeopático). Prática que, segundo a autora, decorre da convergência entre as ideias de Kardec e as de Hahnemann, criador do método homeopático. Os conceitos de "princípio espiritual" e de "força vital" difundidos por Hahnemann iam ao encontro à concepção espírita de que o ser humano possui dois corpos - o corpo material e o corpo espiritual - sendo o "perispírito" o organismo fluídico que une o "corpo" ao "espírito". Devido a esta aproximação entre as duas doutrinas, a homeopatia foi adotada como prática corrente nos tratamentos de saúde. O serviço prestado por médiuns receitistas teve à época uma grande demanda, por conta principalmente da inexistência de atuação do Estado na prestação de serviços de saúde às populações pobres.

No Rio de Janeiro, por exemplo, não havia, pelo menos até metade do século XIX, atendimento médico-hospitalar público, cabendo às organizações beneficentes privadas, como a Santa Casa de Misericórdia, a prestação desses serviços. Como solução deste problema, muitas pessoas recorriam aos trabalhos dos curandeiros e receitistas. Estes últimos, em especial, apresentavam como vantagem o fato de não cobrarem pelos serviços, prática que se deve à orientação moral da doutrina espírita: a "cura" não sendo realizada pelos homens, mas, segundo a crença, pela ação dos "espíritos", não cabe ao médium receitista, tido como "instrumento da caridade cristâ", pagamento ou qualquer recompensa pecuniária. Damazio (1994, p. 93) informa que o sucesso dessa prática entre as "populações carentes" pode ser aquilatada pelo registro realizado no ano de 1905: somente na Federação Espírita Brasileira foram prescritas 146.589 receitas homeopáticas através do seu "Serviço de Assistência aos Necessitados".

O fato é que a crescente difusão dos médiuns receitistas e dos curandeiros chamou a atenção do clero católico e dos médicos, estes preocupados em manter o monopólio da prática medicinal e, aqueles, atentos às expansões de crenças alheias às da religião católica. Foram principalmente esses dois grupos que acabaram por pressionar pela criação, no Código Penal

Debates do NER, Porto Alegre, ano I6, N. 27, P. 385-405, JAn./Jun. 2015 
de 1890, de dois artigos que coibiam práticas de medicina não alopáticas e fórmulas mágicas, discordantes das crenças católicas. Tal pressão, como lembra Damazio (1994), resultou na elaboração dos artigos contidos no capítulo terceiro ("Dos crimes contra a saúde pública”) do Código de 1890, que estabeleciam como crimes:

Art. 156- Exercer a medicina em qualquer de seus ramos, a arte dentária ou a farmácia; praticar a homeopatia, a dosimetria, o hipnotismo ou o magnetismo animal, sem estar habilitado segundo leis e regulamentos;

Art. 157- Praticar o espiritismo, a magia e seus sortilégios, usar de talismãs e cartomancias para despertar sentimentos de ódio ou amor, inculcar curas de moléstias curáveis ou incuráveis, enfim, para fascinar e subjugar a credulidade pública (op. cit., p. 94).

Ao classificar práticas de cura por meio mediúnico como "curandeirismo" e "charlatanismo", o Código Penal de 1890 enquadrou o espiritismo, assim como as demais religióes mediúnicas do país (candomblé, umbanda, quimbanda e outros) na categoria de "magia". Começa aí o embate pela busca de sua legitimidade no Brasil como religião. Nesse sentido, Emerson Giumbelli (2008) mostra como o espiritismo em particular se inseriu historicamente no espaço público e como estabeleceu relaçóes com o Estado (notadamente através de seus dispositivos jurídicos) na busca de legitimidade social.

No início do século XX, existia um debate jurídico bastante intenso para avaliar se o conceito de religião poderia ser aplicado aos cultos mediúnicos, dirigidos principalmente para a questão da saúde pública, um tema que, de acordo com Giumbelli (2008), norteava as reflexôes e discussões de uma grande massa da população brasileira daquele período. As repercussões desses debates serviram para demonstrar que a noção de liberdade religiosa se impunha por meio de regulação direta do Estado sobre práticas religiosas.

O Código Penal republicano, que criminalizava o "espiritismo" e a magia, teve os artigos relativos a esses temas suspensos somente depois de 1940. Em sua defesa, os espíritas investiram na afirmação de que as atividades que

Debates do NER, Porto Alegre, ANo i6, N. 27, P. 385-405, JAN./JUn. 2015 
praticavam não eram mágicas, mas "religiosas", lançando mão da categoria "caridade" para sustentar a tese. Eles afirmavam que as curas mediúnicas realizadas nos centros espíritas não visavam à recompensa financeira: as práticas terapêuticas utilizadas tinham motivação religiosa, eram ato de caridade. Assim, a legitimidade que a prática terapêutica espírita conquistou à época adveio de sua aproximação com o Estado por meio da assistência social, atividade que lhe garantiu o papel de "colaboração" com o Estado, modalidade que veio a se consolidar a partir da Constituição de 1934.

\section{ESPIRITISMO E ASSISTÊNCIA SOCIAL}

Alguns autores (Cavalcanti, 1983; Greenfield, 1999) apontam que no Brasil a cura e a assistência social aos pobres fazem parte de um mesmo circuito, o da caridade espírita. Interessei-me pelo tema depois de fazer uma prospecção inicial sobre a prática de cura. $\mathrm{O}$ objetivo era compreender como que, sob o lema da caridade, o espiritismo inseriu-se na sociedade brasileira, difundindo-se entre as classes populares.

A prática da caridade entre os espíritas é uma norma, fundamento de seu ethos. No espiritismo tudo é caridade, pois qualquer "trabalhador" ou "médium" de um centro espírita "doa" suas energias e esforços em prol do "outro", numa ação de "amor ao próximo". No entanto, há práticas institucionalizadas e foi em busca delas que meu primeiro passo foi me dirigir à Federação Espírita do Paraná para saber: a) quantos centros espíritas eram filiados à Federação; b) que tipo de serviços assistenciais eram prestados por essa e pelos centros ligados a ela; c) como se organizavam as atividades mais comuns de assistência social. Munido de um fôlder no qual constavam os centros espíritas do Paraná ligados à Federação, iniciei um programa de visita a alguns deles localizados na capital paranaense. Primeiramente, através de aplicação de questionário, procurei mapear quais eram e com que frequência aconteciam as atividades de assistência. Ao todo foram visitados sete centros espíritas de Curitiba, nos quais entrevistei os presidentes ou diretores dos departamentos de assistência social.

Debates do NER, Porto Alegre, ano I6, N. 27, P. 385-405, JAn./Jun. 2015 
A partir destes dados, escolhi o Centro Espírita Ildefonso Correia para realizar a pesquisa etnográfica, por ser este um dos centros mais antigos de Curitiba e por suas atividades se assemelharem de um modo geral às realizadas nos outros centros espíritas visitados, o que demonstra certa homogeneidade no que se refere ao tipo dos serviços prestados pelos centros filiados à Federação (distribuição de alimentos, roupas e utensílios domésticos, manutenção de asilos, creches, hospitais e albergues, alfabetização de crianças e adultos e assistência a famílias, dentre outros). A pesquisa de campo objetivou identificar como o conceito de ação social se realiza na prática da caridade espírita, informando modalidades do discurso sobre a assistência social espírita, bem como suas práticas, tal como apresentam-se na capital paranaense. Teve-se como foco duas instituições: a) o Centro Espírita Ildefonso Correia (CEIC) e; b) o Lar Fabiano de Cristo. Em ambas, lançou-se mão da observação participante, de entrevistas semiestruturadas e de pesquisa documental (acesso a matérias de jornal, relatórios, fichas e manuais). No CEIC, participei das atividades realizadas às quintas-feiras com as gestantes e nutrizes, assim como, mas com menor frequência, do Clube de Mães realizado aos sábados. O Lar Fabiano de Cristo foi o outro foco privilegiado da pesquisa, pois se tratava de uma iniciativa de assistência que se dava fora do ambiente de um centro espírita. Com isso, procurei perceber as aproximaçôes e distinçôes de ambos os trabalhos numa perspectiva comparativa. A proposta de trabalho foi analisar comparativamente as práticas de assistência desenvolvidas por leigos nos próprios centros espíritas (o grupo de gestantes do CEIC) e as desenvolvidas em instituições educacionais/ profissionalizantes, conduzidas por profissionais (tendo como referência o Lar Fabiano de Cristo). Privilegiaram-se como informantes os responsáveis pela direção dos serviços assistenciais dos centros e instituições espíritas e também, mas em menor medida, os beneficiários das açôes empreendidas por essas entidades.

O CEIC é um dos centros espíritas mais antigos da cidade de Curitiba; sua data de fundação é de 22 de setembro de 1936 e desde então a entidade vem desenvolvendo atividades assistências e de promoção humana. 
O espiritismo divide suas atividades em duas categorias: assistência material e assistência espiritual. No CEIC, a assistência espiritual é fornecida através dos grupos de estudo da doutrina espírita, de aplicação de passes, promoção de palestras e pelo atendimento fraterno, tendo em média uma frequência semanal de quinhentas pessoas. $\mathrm{O}$ centro conta com cerca de cento e trinta trabalhadores (voluntários e estudantes da doutrina que, de alguma forma, participam da execução e da organização das atividades desenvolvidas). A assistência material do CEIC dispõe de sessenta vagas para os dois dias designados à assistência social - quintas-feiras e sábados. Às quintas-feiras funciona o Grupo de Gestantes e Nutrizes, que é composto por: a) gestantes socialmente carentes que podem se inscrever no programa a partir do terceiro mês de gestação até o parto (com uma permanência mínima de dez semanas e máxima de vinte e cinco semanas); e b) nutrizes carentes de recursos materiais advindas do grupo de gestantes e por seus filhos recém-nascidos (permanência máxima de vinte e quatro semanas). As reuniões acontecem semanalmente com duração de três horas (das $14 \mathrm{~h}$ às $17 \mathrm{~h}$ ) e se dividem em três partes: inicia-se com a realização de uma prece de entrada seguida de uma aula de evangelização, na qual são apresentadas a doutrina espírita e as noções de higiene e de puericultura. A evangelização termina normalmente às $15 \mathrm{~h} 45 \mathrm{~min}$, quando então são aplicados os passes a todas as assistidas que desejarem. Depois é feito um lanche por cerca de quinze minutos e na última parte se oferecem aulas de artesanato e culinária, durante as quais as assistidas aprendem a fazer crochê, fuxico, acolchoados, alguns doces e salgados. Concomitante a isso, é realizada, em uma sala separada, a evangelização de crianças (do berçário aos doze anos). Aos sábados, tem-se o Clube de Mães, cujas atividades se assemelham às do grupo de gestantes e nutrizes. Além das aulas de evangelização, de costura, artesanato e de introdução ao espiritismo, a assistência social do CEIC realiza bazares de roupas, calçados e utensílios domésticos, garantindo a participação de seus assistidos por meio da distribuição de vale-transporte e de uma cesta básica semanal para aqueles que estejam frequentando regularmente os serviços da casa.

Debates do NER, Porto Alegre, ano I6, N. 27, P. 385-405, JAn./Jun. 2015 
O trabalho etnográfico no CEIC deu-se com maior frequência no grupo de gestantes e nutrizes. Participei ao todo de treze reuniōes desse grupo entre os meses de setembro e dezembro de 2009, enquanto no Clube de Mães estive presente em cinco oportunidades (de setembro a novembro do mesmo ano). Em ambas, fiz uso de observação participante, entrevistas semiestruturadas realizadas com os dirigentes e algumas assistidas, além de pesquisa documental (relatórios, manuais etc.).

Primeiramente, quis saber como as assistidas eram atraídas e os critérios para o credenciamento destas nos programas de assistência do centro. De acordo com uma das responsáveis pela elaboração e organização das atividades assistenciais do CEIC, são as próprias mulheres que vêm à procura de ajuda. "Seria muito mais dificultoso ir até os bairros que são, na sua maior parte, dominados pelo tráfico de drogas", segundo ela. Outra trabalhadora a quem perguntei como era feita a inscrição do público atendido respondeu que:

[...] quando elas [as mulheres] vêm, o primeiro passo nosso é pegar os dados pessoais. Depois, a gente procura fazer a ficha, saber o perfil delas. Por exemplo, avós, solteiras sem filhos, pessoas empregadas e com renda não fazem parte do nosso perfil de atendimento, porque têm muitas aqui que não trabalham, que não têm sustento. Então, a gente procura avaliar desta maneira: a mais carente fica. A gente faz uma ficha com todos os dados, procura saber sobre a família, como é que é em casa, onde moram, que tipo de casa elas têm [...]. Elas nos contam qual é a necessidade material delas e daí a gente vai fazer a visita para ver em que o centro pode ajudar. A gente tendo condições de ajudar, a gente ajuda com geladeira, fogão, estas coisas básicas que muitas delas não têm mesmo. A gente vai para lá ver qual é realmente a urgência e a necessidade, a necessidade maior é atendida. (Trabalhadora do CEIC, entrevista realizada em 31 de outubro de 2009)

À coordenadora do grupo de quinta-feira, indaguei qual era a característica das mulheres que procuravam os serviços assistenciais do CEIC:

[...] as mães vêm para o grupo quando gestantes e permanecem depois como nutrizes. São mães que estão completamente desarmonizadas, desorientadas,

Debates do NER, Porto Alegre, ANo I6, N. 27, P. 385-405, JAN./Jun. 2015 
algumas querendo dar o filho, mães que sofreram estupro, que tentaram suicídio e, muitas vezes, elas não querem aceitar esta gestação. $O$ nosso trabalho não é apenas assisti-las materialmente, mas muito mais nas questōes morais e espirituais. Porque esta é a finalidade: é promovê-las como seres humanos para serem aceitas dentro da sociedade em que vivemos. Muitas delas são carrinheiras e, durante o período de gestação, elas ainda continuam puxando carrinho, porque muitas delas foram abandonadas pelos companheiros. A grande maioria tem uma família bem desestruturada. Poucas são as que desempenham a função de empregada doméstica, poucas trabalham com a carteira registrada, a maioria ou está desempregada ou é carrinheira. (Coordenadora do grupo de gestantes e nutrizes do CEIC, entrevista realizada em 08 de outubro de 2009)

Percebe-se que os critérios de definição da clientela obedecem principalmente ao grau de carência socioeconômica das famílias que procuram o atendimento assistencial. Muitos trabalhadores reconhecem que o grande chamariz para atrair o público atendido é o alimento doado, assim como a garantia de participação nas atividades deve-se ao fornecimento de vale-transporte. Os informantes entendem essa prática como primeiro passo de um trabalho cujo fim último é a transformação pessoal; acreditam que a pessoa vem em busca de uma coisa material e receba outra bem mais valiosa, os ensinamentos da doutrina espírita. Os trabalhadores costumam dizer que os alimentos, as roupas e os utensílios doados se desfazem com o tempo, mas os ensinamentos são eternos, nunca se perdem.

É relevante destacar que, a partir da década de 1990, a política de assistência social, liderada pela Federação Espírita Brasileira, pretendeu introduzir uma mudança na maneira como era realizado o serviço assistencial espírita. De acordo com a coordenadora do grupo de gestantes e nutrizes, o trabalho no CEIC acontecia de uma forma diferente: "as mães vinham, recebiam os alimentos, o enxovalzinho e iam embora, eram dispensadas. O trabalho se constituía nisso, era o assistencialismo. Hoje não, hoje nós preparamos as aulas para que possam atender a realidade do dia a dia delas". Em sua visão, não se fala mais em assistencialismo, mas em educação. No caso das populações "carentes", essa educação visa a compreender as razões do sofrimento e das mazelas sociais:

Debates do NER, Porto Alegre, ano I6, N. 27, P. 385-405, JAn./Jun. 2015 
[...] muitas das mães são revoltadas, elas dizem 'porque eu vivo nesta miséria?', 'por que eu passo por tantas dificuldades?', 'por que Deus é injusto?'. Quando você fala para elas que Deus é justo e fala em reencarnação, começa a abrir um leque de esperanças. Você começa a mostrar que elas vão ter oportunidade de uma vida melhor em outra existência, que elas provavelmente não aproveitaram bem as oportunidades que já foram dadas e hoje elas têm que passar por isso. Então quando você faz com que ela entenda isso, a vida passa a ser mais bem aceita. Esta é a grande oportunidade que nós temos em nossas mãos, de ajudar essas pessoas. A doutrina está aí e nós devemos ser os grandes divulgadores, e não apenas no falar, mas no exemplificar. Porque o falar é muito bonito, mas se você não exemplifica, se você não vivencia, perde toda a credibilidade. (Coordenadora do CEIC, entrevista realizada em 08 de outubro de 2009)

Outro ponto enfatizado concerne à preocupação de não gerar, por parte dos assistidos, uma dependência permanente em relação aos serviços prestados. A coordenadora do serviço assistencial de um dos primeiros centros espíritas que visitei em meu mapeamento inicial de pesquisa, ao ser indagada sobre a diferença entre caridade e assistência social, afirmou que:

[...] caridade é você dar oportunidade, e assistência é você ensinar a pescar. Porque não adianta fazer só a caridade, o que não é fácil é você ensinar a pescar. O Divaldo (Pereira Franco, médium da instituição espírita baiana Mansão do Caminho) uma vez contou que encontrou uma mulher emocionada, que disse a ele que a mãe e a filha dela foram assistidas pelo centro dele. Poxa, somando tudo dava uns quarenta anos que esta família era atendida pelo Divaldo! É com isso que ele fica bravo, porque se elas estavam há tanto tempo no centro é porque nada fizeram da vida. Na verdade, o que a gente quer é que as pessoas andem com as próprias pernas, que não fiquem dependentes de nós. O que a gente faz é promoção humana, não assistencialismo. (Coordenadora da Ação Social do Centro Espírita Abib Isfer, entrevista realizada em 06 de outubro de 2009)

Interessante notar nessa fala e em muitas que ouvi em campo que a noção de caridade, definida de forma abrangente como "valor universal praticado como um dever moral", serve para definir práticas distintas: assistencialismo 
e "promoção humana”. Nesse sentido, Marcelo Camurça (2003) defende a tese de que haveria atualmente uma tentativa de "colonização da filantropia", através de discursos modernos de "educação para a cidadania" e de "garantia dos direitos sociais". O artigo 203 da Constituição Federal de 1988 considera a assistência social "[...] um dever do Estado e direito do cidadão", artigo esse regulamentado pela lei 8.742, a lei Orgânica de Assistência Social (LOAS) que define a assistência social como "[...] política de seguridade social não contributiva, que provê os minimos sociais, realizada através de um conjunto de açôes de iniciativa pública e da sociedade, para garantir $o$ atendimento às necessidades básicas" (1993, cap. I, art. $1^{\circ}$, grifo nosso).

O espiritismo afirma essa concepção de cidadania, mas acrescenta elementos alheios à lógica do Estado, uma vez que entende que, mais do que uma casa prestadora de serviços (doação de alimentos, de roupas etc.), o centro espírita deve ser um espaço de convivência fraterna, um campo para se "exercitar a construção de relaçôes". Sob esta ótica, o "assistido", na sua condição de cidadão (sujeito de direitos), é assim definido pelos centros espíritas:

[...] gosta de estar, sente-se bem de estar, onde é recebido como é, com o seu jeito, com as suas características, com a sua forma de falar e onde pode encontrar quem se dispõe a conversar com ele de forma natural, de irmão para irmão, dando-lhe tempo para que caminhe do ponto em que se encontra e, em se desvelando, vá permitindo acesso ao seu coração e acabe abrindo-se também para o coração do outro [...] (Manual de Apoio para as Atividades do Serviço de Assistência e Promoção Social Espírita, 2000, p. 8).

Em virtude da defesa da fraternidade como princípio, distinto da lógica do mercado e do Estado, não acredito, principalmente em contextos religiosos de assistência, na existência do risco de eliminação da estrutura de dádiva em instituições de filantropia e caridade. Tratar-se-ia, a meu ver, muito mais de uma apropriação singular, por parte dessas instituições, do conceito de cidadania, apropriação essa que reúne não somente valores definidos pelo Estado, como a questão dos direitos, mas também categorias de origem religiosa, como a ideia de fraternidade.

Debates do NER, Porto Alegre, ano I6, N. 27, P. 385-405, JAn./Jun. 2015 
O trabalho de campo no CEIC permitiu-me ter um acesso mais direto à Federação Espírita do Paraná, pois muito dos trabalhadores desse centro ocupam cargos na Federação. Devido a esse duplo contato, tomei conhecimento da Fundação Hildebrando de Araújo, cujo diretor fora me apresentado lá mesmo no CEIC. Por meio dela, eu poderia conhecer melhor as instituições espíritas que desenvolviam trabalhos em "áreas carentes". O objetivo da Fundação Hildebrando de Araújo é justamente transferir recursos a instituições filantrópicas que visam à "reversão do quadro de exclusão social das comunidades”. Uma das instituições conveniadas à Fundação é a Alvorecer Ação Social e Educacional, cuja missão é " [...] prevenir a delinquência infanto-juvenil e promover de modo integral as famílias, atuando nas causas que geram a miséria, material, social, moral-ética e espiritual, contribuindo para o equilíbrio das famílias" (Relatório anual da entidade, 2008, p. 8).

Desde sua fundação, em 1992, a Alvorecer sempre teve como foco a profissionalização de adolescentes, mas, como não detinha uma metodologia própria de desenvolvimento de trabalho junto a famílias carentes, acabou se vinculando ao Lar Fabiano de Cristo, que na época (início da década de 2000) estava buscando uma parceria com uma entidade espírita de Curitiba. É por meio deste trabalho integrado da Alvorecer com o Lar Fabiano de Cristo $^{3}$ que se pretende a realização da "promoção integral das famílias".

3 O Lar Fabiano de Cristo, fundado em 1958 a partir de uma ideia defendida por Carlos Torres Pastorino e apoiada por outras personalidades espíritas da época (Francisco Cândido Xavier, Jaime Rolemberg de Lima, Divaldo Pereira Franco, dentre outros), objetivava concretizar propostas que pudessem beneficiar "a infância carente e desvalida". Foram criadas cinco "faixas" de assistência centrando seus trabalhos nas seguintes áreas: a) 1a Faixa - "Colocação Familiar em Lares Substitutos" - visa a colocar crianças órfãs ou com pais interditados em um contexto familiar através de guarda permanente ou adoção; b) 2a Faixa - "Abrigos Provisórios" - acolhe crianças cujos direitos encontram-se temporariamente violados ou ameaçados com vistas a promover a reintegração familiar ou colocação em família substituta ou extensa na forma de abrigo; c) 3a Faixa - "Promoção Integral da Família" - atende, através de programas de apoio sociofamiliar e de orientação socioeducativa, famílias em estado de extrema pobreza ou miséria inscritas nas 
O local onde funciona a Alvorecer, a partir do momento em que esta se conveniou ao Lar Fabiano de Cristo, passou a ser chamado de Unidade de Promoção Integral (UPI) Joana D’Arc, integrando assim a “3a Faixa” de assistência. Para realizar a "promoção integral das famílias", a UPI conta com dois programas, o de orientação sociofamiliar e o de apoio socioeducativo. O primeiro (orientação sociofamiliar) é subdividido em três subprogramas: a) "educação e acompanhamento social"; b) "apoio às necessidades básicas" e; c) "cidadania". O programa de apoio socioeducativo subdivide-se em: a) "educação infantil"; b) "desenvolvimento criativo e complemento escolar" e; c) "profissionalização". As atividades desenvolvidas pela Alvorecer são as seguintes: a) "Programa do Aprendiz (Lei 10.097/00), centrado em cursos de profissionalização (assistente administrativo, digitação, informática, desenvolvimento de habilidades básicas etc.); b) cursos de higiene e saúde, boas maneiras, educação para a cidadania e educação ambiental, etiqueta e relações interpessoais; c) desenvolvimento criativo e complemento escolar, para crianças de seis a treze anos, em contraturno escolar; d) educação e acompanhamento social de crianças e adolescentes junto às escolas de ensino regular; e) promoção integral das famílias. Além disso, a UPI oferece também aos "assistidos" ou "coparticipantes" (como lá são denominados) a oportunidade de participarem dos grupos de "geração de renda", que incentivam o "empreendedorismo" nas comunidades e das aulas de "Educação do Ser Integral".

Por "promoção integral", entende-se o atendimento a famílias em situação de "vulnerabilidade social", com renda per capita abaixo de um quarto do salário mínimo. O vínculo destas com a instituição tem duração de, no máximo, cinco anos. $\mathrm{O}$ primeiro passo desse processo se

UPI - Unidades de Promoção Integral - próprias ou parceiras do Lar Fabiano; d) 4a Faixa - "Apoio Emergencial" - assiste de um modo descontínuo e em caráter emergencial, por meio de apoio material e/ou encaminhamentos à rede de serviços públicos e privados, pessoas não inscritas em seus programas; e) 5a Faixa - "Promoção Integral do Idoso" implementa ações socioeducativas inclusivas e específicas para pessoas de terceira idade em estado de pobreza extrema. Na época em que fiz a pesquisa, o Lar Fabiano estava presente em quase todos os Estados brasileiros e atendia a cerca de cem mil pessoas em nível nacional.

Debates do NER, Porto Alegre, ano I6, N. 27, P. 385-405, JAn./Jun. 2015 
dá com a chegada espontânea das famílias (na maior parte das vezes, das mulheres) à instituição, momento em que é feita a primeira entrevista. Depois desta, faz-se uma "visita domiciliar" com o objetivo de realizar um diagnóstico das condições de vida das famílias e saber se elas se encaixam no perfil de atendimento da instituição. Em caso afirmativo, faz-se o Plano de Qualidade de Vida (PQV), com a mediação de assistentes sociais: este consiste no estabelecimento de metas de curto, médio e de longo prazo (metas como "inserção no mercado de trabalho", aquisição de casa própria, abandono do uso de drogas etc.). O Plano de Qualidade de Vida (PQV) tem por finalidade contribuir para que as "famílias carentes" consigam perceber todas as necessidades que tenham, "necessidades de ordem material, social, moral-ética e espiritual", para que ela veja quais são as causas da "situação problemática" em que se encontram e quais as ações necessárias para eliminar essas causas.

Interessante destacar as principais motivações que levam as pessoas a procurarem os serviços da UPI Joana D’Arc. Sobressaem-se os termos “ajuda”, "auxílio", a intenção de colocar os filhos na instituição com a preocupação desses não ficarem sozinhos em casa durante o expediente dos pais e o interesse de se ter uma renda extra através do Programa do Aprendiz. Numa entrevista com adolescentes da instituição, indaguei qual era o objetivo das famílias desses jovens ao se inscreverem no Lar Fabiano de Cristo:

A intenção da minha mãe era que eu fizesse este curso [do Programa do Aprendiz] para que depois eu arrumasse emprego. Daí ela foi conhecendo tudo, a ajuda que eles dão para as famílias, todo o auxílio. A minha mãe, no caso, tem problema de saúde. Quando a gente não tem condições de comprar o remédio que mandam fazer, a gente vem aqui e eles dão. Eles fazem documentação também: a minha mãe, por exemplo, não tinha $\mathrm{CPF}$, e eles fizeram aqui. (Adolescente inscrito no Programa do Aprendiz, entrevista realizada em 17 de abril de 2010)

Outra "coparticipante", mãe de um dos adolescentes atendidos pela UPI, afirma que a contribuição do Lar Fabiano de Cristo para ela acontece da seguinte forma:

Debates do NER, Porto Alegre, ANo I6, N. 27, P. 385-405, JAN./JUn. 2015 
É uma ajuda muito boa, é o meu braço direito, não tanto pelo alimento, mas para deixar as crianças mesmo, porque o meu horário é muito puxado. Eu conheci (a instituição) através de uma amiga minha. Eu estava com muita dificuldade, estava morando num porãozinho com as crianças, daí ela disse que aqui eles ajudavam. Eles já me deram cesta básica, roupa, remédio e a televisão que as crianças assistem. ("Coparticipante” da UPI Joana D’Arc, entrevista realizada em 17 de abril de 2010)

No momento de minha pesquisa, o Lar Fabiano de Cristo atuava em duas áreas de Curitiba: no Bairro Alto e no Cajuru, onde eram atendidas cerca de 160 famílias, totalizando aproximadamente 650 pessoas. A instituição contava com aproximadamente vinte e cinco funcionários (assistentes sociais, psicólogos, educadores, orientador técnico, gestor social etc.) e quarenta voluntários, estes oriundos geralmente do Centro Espírita Irmã Scheilla e outros ligados à Federação Espírita do Paraná.

Uma das tarefas em que os voluntários se inserem na UPI Joana D’Arc é a "Educação do Ser Integral". O Lar Fabiano de Cristo adota uma proposta pedagógica que inicialmente era denominada "Educação do Espírito", alterada depois para "Educação do Ser Integral”. Sua fundamentação, segundo seus idealizadores, é pautada por uma "visão holística do ser". Considera-se "ser integral" a totalidade da pessoa, constituída por suas várias dimensões: "física, emocional, mental e espiritual", cuja educação objetiva o "conhecimento das leis que regem a vida e a harmonização das dimensões da totalidade individual e sua integração com as totalidades maiores em que se incluem: a social, a ambiental e a cósmica". Os princípios básicos que norteiam a Educação do Ser Integral são:

a) a perfectibilidade do ser humano; b) a visão holística do ser, sendo o espírito a sua essência imortal em contínuo processo de evolução; c) o conhecimento e integração nas leis universais como meio de libertação e crescimento; d) a educação dos sentimentos como objetivo principal da existência, efetivada nas relações interpessoais e no respeito às leis da natureza (Comunicação institucional do Lar Fabiano de Cristo, 2007, p. 1).

Debates do NER, Porto Alegre, ano I6, N. 27, P. 385-405, JAn./Jun. 2015 
Educar o espírito implica aqui o "desabrochamento das sementes divinas que constituem a essência humana", atividade que exemplifica a prática de um dos lemas preferidos do Lar Fabiano: "assistir é educar; educar é orientar na direção do bem”. A proposta da Educação do Ser Integral é considerada particularmente importante para os "grupos socialmente mais carentes", pois estes estariam mais expostos às "influências desagregadoras" da sociedade. Vale ressaltar que a transformação e a superação alcançadas através dessas aulas só serão atingidas se houver, por parte dos "assistidos", aceitação dos valores transmitidos. A adesão dos educandos é, portanto, considerada fundamental para que a "Educação do Espírito" atinja seus objetivos.

Vemos, assim, que este modelo de atuação se assemelha àquele implementado no grupo de mães do CEIC, na medida em que concebe a "transformação social" como resultado de ações educativas que objetivam a "elevação moral e espiritual" dos indivíduos delas participantes. Por outro lado, a etnografia por mim realizada nestas duas instituições espíritas demonstrou que, apesar de guardarem muitas semelhanças, elas contêm também algumas distinções. Percebeu-se uma ligeira diferenciação entre o trabalho realizado no CEIC (feito somente por leigos ou voluntários) e o feito no Lar Fabiano de Cristo, que conta com técnicos, dentre eles, assistentes sociais, psicólogos e gestores sociais.

Ao ser conduzido por profissionais e ter sua administração em moldes empresariais, o Lar Fabiano de Cristo serviria como um caso exemplar da associação apresentada por lideranças espíritas entre caridade e cidadania. A diferença estaria na participação de espíritas em conselhos vinculados ao Estado (tal como o Conselho Municipal de Assistência Social de Curitiba) e em fóruns organizados pela sociedade civil (por exemplo, o Fórum da Aprendizagem, do qual também participei), em função da qual se promove uma reavaliação do conceito de caridade. $\mathrm{O}$ assistido assume nesse caso um novo status: de sujeito passivo, objeto da ação do outro, para ser visto como sujeito de direitos; a caridade não significa ato de benevolência, mas prática de contribuição à construção da cidadania.

Debates do NER, Porto Alegre, ANo I6, N. 27, P. 385-405, JAN./JUn. 2015 


\section{CONSIDERAÇÕES FINAIS}

Quais são as formas e de que modo as instituições espíritas intervêm na sociedade brasileira? A pesquisa realizada procurou mostrar que um elemento intrínseco ao espiritismo, justamente o mais enfatizado no percurso feito no Brasil, foi o que conferiu visibilidade à doutrina no espaço público, ou seja, o princípio da caridade. A concepção de evolução espiritual, na qual cada indivíduo, através do cumprimento de várias etapas ou encarnaçôes, realiza seu aperfeiçoamento moral, justifica a importância conferida à caridade, pois sem ela a evolução não se faz possível. A escolha da caridade enquanto uma força promotora da evolução guarda ainda uma concepção da realidade social firmada segundo princípios morais, uma vez que a desigualdade social (ou material) comumente pode ser associada à faltas (ou méritos) de ordem individual cometidas em existências anteriores, que repercutem de alguma forma no plano espiritual.

As instituições espíritas, quase sem exceção, desenvolvem alguma forma de assistência social, e a caridade, nesse ponto, é o que anima e fundamenta essas atividades. Levou-se em consideração na análise a distinção entre o que é denominado por "caridade material" e "caridade espiritual". Enquanto esta designa as "práticas mediúnicas", os "passes", a "água fluidificada", enfim, tudo aquilo que provoca a recuperação ou a imunização física ou "espiritual” das pessoas que se submetem a tais práticas, aquela indica as atividades de assistência social, como as doações de roupas e alimentos, as instituições filantrópicas de saúde e educação, dirigidas às "populações carentes”. Não importa qual seja a forma de assistência prestada sob o preceito da caridade, sua relevância no funcionamento e na organização das instituições espíritas é sempre um elemento fundamental; é difícil encontrar um centro espírita que não faça aplicação de "passes" ou que não preste alguma assistência, desde distribuir alimentos até manter creches, abrigos, asilos etc. Está se falando aqui apenas de instituiçôes que se definem como "religiosas", mas foi preciso também levar em consideração nesta pesquisa as entidades que,

Debates do NER, Porto Alegre, ano I6, N. 27, P. 385-405, JAn./Jun. 2015 
embora ligadas ao espiritismo, declaram não ter fins religiosos. Trata-se das instituições filantrópicas que, dada a importância e a quantidade de trabalhos de assistência social, apresentam igualmente uma diversidade de formatos, de modos de atendimento, de percursos históricos e de relaçóes com outras organizaçóes e agentes sociais. De forma particular, elas resolvem como se dá a relação entre a existência de atividades eminentemente religiosas e a prestação dos serviços assistenciais para uma clientela em que a adesão ao espiritismo não se faz obrigatória.

Chamou-se atenção à associação que vem sendo realizada por algumas lideranças espíritas entre caridade e cidadania. Como afirma Giumbelli (1997), essa associação manifesta-se, por exemplo, na crescente participação de espíritas em conselhos governamentais e em fóruns organizados pela sociedade civil, participação essa que se explica pela tradição e representatividade que as instituições espíritas alcançaram historicamente no seio das atividades de assistência social. Qual seria então a concepção espírita de "política"? Num primeiro aspecto, a atividade "política" só é compreendida de uma forma positiva se ela ocorrer numa esfera individual, ou seja, na medida em que cada espírita procura exercer, sob a orientação da doutrina, seus direitos e deveres de "cidadão". Na esfera institucional não se permite, sob nenhuma hipótese, que o indivíduo atue em nome do espiritismo com fins estritamente políticos. Uma das falas da presidente da Alvorecer demonstra bem isso: "Nós não tomamos posicionamento político, não apoiamos partidos, candidatos, não fazemos campanhas de forma nenhuma”. "Entrar para a política" significa, para eles, exercer atividades no plano estatal; a existência da política, dessa forma, só aconteceria no interior do Estado e se expressaria através das divisões partidárias, um domínio, segundo eles, marcado por diversos "conflitos, conluios e intrigas", características essas que se fazem distantes do ambiente das relações que os espíritas desejam ter entre si e com a sociedade em geral. Isso não quer dizer que eles não tenham o anseio de melhorarem a realidade social, muito pelo contrário, os espíritas apenas entendem que essa transformação se dê não via política, mas através do melhoramento de indivíduos, por meio de uma "educação 
de valores ético-morais" universalizante. A resolução dos problemas sociais dependeria de uma despolitização das questôes humanas, obedecendo assim a uma lógica distinta da lógica política, qual seja, uma lógica na qual a "solidariedade", a "caridade" e o "gradual desenvolvimento das potencialidades individuais" imperassem.

Quanto a essa concepção de política dos espíritas, Giumbelli (1997) aponta para algumas descontinuidades que foram notadas nesta etnografia: a participação dos espíritas em conselhos e fóruns, espaços de exercício da política, sinaliza que entre o doutrinário e o político não haja a ruptura defendida, pelo menos nos moldes anteriormente mencionados, pois entende-se que o espiritismo concebe o seu envolvimento nessas instâncias como uma ocasião apropriada para expressar seus princípios e ideais. A própria noção de "política" perde o seu sentido usual, de qualquer coisa ligada exclusivamente ao Estado e aos partidos, para ser compreendida como algo que atravessa todas as relações sociais, como um atributo da própria experiência humana. Nesse sentido, as entidades espíritas concebem-se enquanto participantes de uma "sociedade civil", em que a pluralidade dos atores e instituições envolvidos e a afirmação de valores democráticos far-se-iam preponderantes. A transformação da realidade e a solução dos problemas sociais não estariam ligadas a uma ordenação do mundo aos valores espíritas, mas à própria participação das instituições nessas instâncias democráticas.

Este novo entendimento acerca do significado da "política" é evidenciado, por exemplo, na relação do princípio da caridade com a noção de cidadania. Qual a significação que a palavra caridade assume nesse contexto? Há um redimensionamento, no contexto da assistência social, do conceito espírita de caridade, haja vista que este deixa de compreender apenas uma ação de benevolência, para se tornar um ato de cidadania, uma prática civil de exercício de direitos.

A crítica ao "assistencialismo" é hegemônica em todos os centros e instituições em que visitei, pois esse sistema se daria, segundo se diz, de um modo pontual e desarticulado das "reais necessidades" de seu público alvo. Ao invés de uma "transformação" e "promoção humana", criar-se-ia uma

Debates do NER, Porto Alegre, ano I6, N. 27, P. 385-405, JAn./Jun. 2015 
dependência dos assistidos aos serviços assistenciais espíritas, não proporcionando, assim, melhora efetiva na vida dessas pessoas. Porém, como nota Giumbelli (1997), essa crítica em si não tem muita coisa de original. A originalidade encontra-se nas tentativas de revisão das práticas assistenciais a partir das demandas dos assistidos. Procurei esmiuçar essa originalidade a partir dos serviços do CEIC e, principalmente, do Lar Fabiano de Cristo, que chamou atenção pelo fato de ser uma organização filantrópica mantenedora de uma série de instituições de assistência social difundidas pelo Brasil cuja administração se dá em moldes empresariais e com a maior parte das suas atividades conduzidas por técnicos.

Como procurei demonstrar, não se trata apenas de uma ressignificação da caridade, mas também de uma maneira peculiar de se apropriar o termo cidadania, pois a ele se associam valores que antigamente eram característicos da caridade, como a solidariedade e a fraternidade, dando ao conceito de cidadania uma conotação moral. Um aspecto importante dessa alteração é o fato de a cidadania atualmente não fazer mais referência somente à esfera do Estado. Para os espíritas, ela estaria sob a responsabilidade dos indivíduos, na medida em que são estes quem detêm os valores morais próprios ao exercício do ser cidadão.

\section{REFERENNCIAS}

ARRAIA, Eduardo. Espiritismo. São Paulo: Ática, 1996.

CAMURÇA, Marcelo. "Caridade, a 'religião civil' dos brasileiros?" Religiāo, ação social e politica, Juiz de Fora: Universidade Federal de Juiz de Fora, 2003.

CAVALCANTI, Maria Laura Viveiros de Castro. O mundo invisivel: cosmologia, sistema ritual e noção de pessoa no Espiritismo. Rio de Janeiro: Zahar, 1983.

DAMASIO, Sylvia. Da elite ao povo: advento e expansão do Espiritismo no Brasil. Rio de Janeiro: Bertrand Brasil, 1994. 
FEDERAÇÃO ESPÍRITA BRASILEIRA. Manual de Apoio para as atividades do serviço de assistência e promoção social espirita. Brasília: FEB, 2000. FEDERAÇÃO ESPÍRITA DO PARANÁ, Memória da Federação Espirita do Paraná no seu centenário: 1902-2002. Curitiba: FEP, 2002.

GIUMBELLI, Emerson. Escolhas religiosas e cidadania. Cadernos de Pesquisa, São Paulo, n. 6, 1997.

- A presença do religioso no espaço público: modalidades no Brasil. Religiāo \& Sociedade, Rio de Janeiro, v. 28, n. 2, 2008.

GREENFIELD, Sidney M. Cirurgias do além: pesquisas antropológicas sobre curas espirituais. Petropólis: Vozes, 1999.

Recebido em: 29/07/2014

Aprovado em: 13/09/2014

Debates do NER, Porto Alegre, ano i6, N. 27, P. 385-405, JAN./Jun. 2015 